\title{
From Theory to Practice to Experience: Building Scholarly Learning Communities in Nontraditional Doctoral Programs
}

\author{
Hank Radda, PhD \\ Dean and Senior Vice President, College of Doctoral Studies \\ Grand Canyon University
}

\begin{abstract}
Demands of the modern workforce, coupled with rapid advances in educational technology, have created a new paradigm of doctoral learning. No longer designed with the traditional academic in mind, doctoral education has expanded to accommodate the expectations, demands, and expertise of working professionals. Simultaneously, traditional academic voices have articulated more vibrant and diverse understandings on the development and socialization of doctoral learners. Considerations of the methods, interventions, and outcomes for the development of scholars are being investigated; as highlighted by Gardner and Mendoza (2010), successful doctoral programs should consider a wider variety of scholarly outputs, development methodologies, and stakeholder perspectives. In this reflection, I focus on the considerations unique to adult learners, with a focus on the scholar-practitioner model. By understanding (and embracing) adult epistemological development, effective doctoral programs can simultaneously meet the needs, schedules, and demands of adult learners in a manner that socializes them for the various expectations of the profession. While the theoretical underpinnings of modern doctoral education have been established in the literature (see Gardner and Mendoza, 2010, for an overview), it is less clear how these andragogical principles translate into the organizational and structural foundations of a scalable doctoral program in a manner that fosters a vibrant learning organization. In this essay, I draw on my experience in creating doctoral programs designed explicitly for the modern adult learner and discuss, in collaboration with current doctoral learners, the impact of these programmatic initiatives on the learning experience.

When discussing nontraditional, scholar-practitioner-oriented doctoral
programs, it is important to highlight the

By understanding....adult epistemological development, effective doctoral programs can simultaneously meet the needs... of adult learners in a manner that socializes them for the...expectations of the professions.
\end{abstract} characteristics that distinguish these unique programs from their more traditional counterparts. Nontraditional doctoral learning is designed for adult learners with 15-25 years of professional experience who enter the program with master degrees and significant knowledge and experience in their current field of practice. As such, there is a dedicated shift in emphasis away from acquisition of content knowledge; rather, the goal is to create opportunities to engage in applied research that synthesizes learners' current expertise and scholarly engagement. These conditions create a unique opportunity to develop a scholarly learning community in innovative ways that capitalize on the strengths, knowledge, and passion of the learners.

Over the past ten years, I have led the doctoral offerings for two universities; embracing a more holistic model, this leadership extends beyond academic oversight to include faculty and support operations. In these universities, the doctoral programs are housed in a separate college (or school) distinct from the parent academic disciplines. I have experience overseeing programs ranging from DM in Management to PhD in Nursing to EdD in Higher Education (this is only a sampling of the range of offerings) and I currently lead doctoral programs offering DBA in Business Administration, $\mathrm{PhD}$ in General Psychology, and EdD in Organizational Leadership. I highlight my experience in this broad range as a means of showcasing the applied nature and focus of these non-traditional advanced 
degrees. In this unique setting, I have had the opportunity to create the programmatic structure that supports scholarly learning communities in a manner that aligns with trends in online education, adult learning theory, and workforce expectations. Although we have achieved considerable success (both in terms of graduates, program growth, and applied scholarship), we are at the early stages of creating the opportunities for greater collaboration in scholarship that takes advantage of interdisciplinary perspectives, geographically dispersed participants (faculty and learners) with unique scholar-practitioner experiences, and enhanced coordinated research agendas for scholarly output.

Reflecting on our initiatives (including both successes and failures), two theoretical assumptions emerge as essential components of programs that foster effective intellectual growth at the doctoral level:

o Adult learners with professional experience have significant overt and tacit knowledge to share and develop.

o Adult learners in these doctoral communities have intentionality to improve their community/organization using the scholarship, critical thinking, and analysis developed throughout their education.

Underlying these assumptions is the need to

foster an interactive community of learners: not simply a cohort to serve as support, nor a social grouping that progresses as a shared collective, but rather, a learning community that is explicitly designed with the needs, goals, and expertise of each individual learner driving the format, content, and progression of interactions.

These types of learning communities often emerge as the natural by-product of

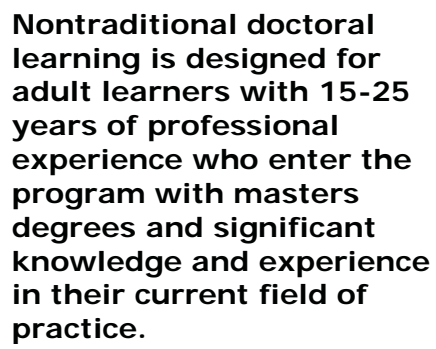
close-knit research groups in a traditional, face-to-face institution; with a single faculty member leading a hand-picked group of prodigies, the natural dynamics of a social group take over to foster an intellectual give-and-take. In contrast, modern online programs must be explicit in the development of a programmatic structure that supports this type of intellectual exchange. While there is obviously not a single, isolated route that institutions must take to foster scholarly learning communities while serving a geographically dispersed population, I will highlight three initiatives that we found to be particularly successful with our learners: intentionality emphasis, residency programs, and scholarly networks.

\section{Intentionality Emphasis}

Taking a developmental approach to building a scholarly learning community (and recognizing the characteristics of learners who choose this type of program), we have been mindful of the transition process as learners enter doctoral education and are introduced to the associated opportunities. Creating conversations with potential learners and prompting them to clarify their intentionality and their understanding of what meanings are associated with entering a doctoral journey is vital to maximize their opportunity for success. We conceptualize the initial application, conversations, essays, orientations, and first few classes as a vital period of engaging doctoral learners. It is a time to encourage reflection by the potential learners on their intentionality; not only their personal positions, but an integrated process of considering their intentionality for professional and scholarly development. We believe that for success they need to enter with a vision and dedication born of their experience and a passion for what they will develop as scholar-practitioners. 
The curriculum of the initial classes is explicitly designed to assist learners in differentiating their conceptualization from a master's to a doctoral program. Emphasis is placed on fostering learners' responsibility for their learning, the questioning of the material, and the early development of critical analysis and reflection. Through an emphasis on independence and intentionality, the program encourages learners' extracurricular involvement in the scholarly learning community. We believe that while it is vital to provide opportunities for scholarly engagement within classes with an integrated curriculum and outside the confines of each class, it is equally important to foster a mindset that prepares learners to effectively take advantage of the initiatives provided.

\section{Residency Programs}

The reality of the modern workforce necessitates the inclusion of online coursework as a foundation of many scholar-practitioner-oriented doctoral programs. While online education has an established record of effectiveness, it is also important to provide opportunities for face-to-face interaction via residency programs. Our unique focus in residency opportunities is to bring the community of scholars together with faculty that are experts in research and dissertation development. Since we have an integrated curriculum that threads content and scholarly inquiry throughout the program in a developmental fashion, the residency is used as a pivotal event to clarify the scholarly goals, ascertain progress, and establish a clear path for the next phase in the learners' program.

During the initial online experience of the program, camaraderie develops in the online classrooms where learners engage in thoughtful and meaningful dialogues around specific course content. When learners meet

\author{
While online education has \\ an established record of \\ effectiveness, it is also \\ important to provide \\ opportunities for face-to- \\ face interaction via \\ residency programs.
} face-to-face for the first time in residency, an immediacy and intimacy of mind (i.e., thinking and understanding of the others' perspectives) emerge in the interactions. The residency program is designed to foster an active community of scholars focused primarily on the development of the prospectus, proposal, and the dissertation. These residency experiences punctuate integrated learning to guide the most difficult part of the doctoral journey.

\section{Doctoral Community Network @}

The Doctoral Community Network (DC) is a scholarly network that recreates many aspects of the residency in a vibrant online community available throughout the doctoral journey. Many individuals that complete a traditional doctoral program report that much of their learning and professional growth resulted from interactions and activities outside the confines of an individual class. Rather, the informal discussions and interactions that occurred in the hallway, coffee shop, or student lounge were just as important as the formal activities that occurred during scheduled classes. The simple proximity and availability of others with shared interests, goals, and content knowledge creates a natural breeding ground for intellectual banter. In nontraditional doctoral programs, faculty and learners often do not have the luxury of physical proximity, so it is vital that institutions create unique opportunities for these students to interact in a scholarly community that does not revolve around a specific course. The Doctoral Community Network (DC) is a learner-driven, scholarly community designed to help learners successfully complete their program of study; it provides a rich collaborative environment that includes resources, roadmaps, references, and tools to support learners in becoming independent scholars (Berman, in press). 
Even though the Doctoral Community Network (DC) is in its adolescence, learners and faculty are already actively engaged in scholarly dialogue resulting in growing research agendas and interdisciplinary scholarship. As learners post research ideas, other learners and faculty reflect, share resources, and encourage articulation of thought. The enhanced scholarly dialogue stems from outside of the classroom (similar to hallway conversations available in face-to-face programs) and capitalizes on the experiences and expertise of our geographically dispersed population. Unlike general social networks, the Doctoral Community Network (DC) explicitly focuses on promoting quality scholarship, fostering successful completion of the program, and encouraging engagement in the larger academic community through opportunities to publish and/or present research.

\section{Conclusions}

Fostering vibrant learning communities for adult learners in nontraditional doctoral programs requires explicit attention to the unique needs of this population. Institutions must design programs that create opportunities for scholarly interactions in a manner that fits the needs, goals, and schedules of the adult learner.

Extending beyond the confines of a single class, effective learning communities emerge when programmatic structure allows adult learners to drive interactions that capitalize on their professional expertise and intentionality. As such, programmatic initiatives must maintain a critical balance between structure and freedom. Successful programs provide the structural foundation that supports and encourages collaboration, yet allows sufficient freedom for doctoral learners to formulate and direct their role within the larger structure. Nontraditional doctoral programs must create opportunities for learners to interact and maximize professional connections in order to capitalize on the broader perspectives and expertise available.

In the following reflective annotations, you will see the progression from the theoretical underpinnings highlighted by Gardner and Mendoza (2010) to the experiences of doctoral learners currently immersed in a nontraditional program designed to foster an integrated scholarly learning community. Through the reflections of doctoral learners on targeted chapters of socialization and development, you see an emerging scholarly learning community. It is heartening to see a resonance between the program vision and the actual experiences of the learners. Clearly, this is an ongoing dialogue where learners, faculty, counselors, and administration collaborate in the creation of scholar-practitioners within a vibrant scholarly community. This exercise, in and of itself, aligns with our inherent process of continually defining, dialoguing, and enhancing our program for graduates to develop purposeful scholarship.

\section{Reference}

Gardner, S., \& Mendoza, P. (Eds.) (2010). On becoming a scholar: Socialization and development in doctoral education. Sterling, VA: Stylus.

Hank Radda, Ph.D., is the Dean of the College of Doctoral Studies and Senior Vice President of Grand Canyon University. GCU offers online and blended learning models supplemented with an innovative virtual Doctoral Community Network - a virtual community of scholarship and practice integrated with the doctoral curriculum. As the former SVP of the School of Advanced Studies for the University of Phoenix, he built a high-performance learning organization to grow and develop their doctoral programs. Hank holds a Master's of Science in Community-School Psychology from the College of New Rochelle and a Doctorate of Philosophy in Clinical Psychology from the Union Institute. 